\title{
Initial survival of coral nubbins transplanted by a new coral transplantation technology - options for reef rehabilitation
}

\author{
Peter van Treeck*, Helmut Schuhmacher \\ Institut für Ökologie, Abt. Hydrobiologie, Universität GH Essen, D-45117 Essen, Germany
}

\begin{abstract}
A new method of coral transplantation is presented. Electrolysis in seawater induces cathodic accretion of calcium and magnesium minerals on an appropriately formed cathode (made of steel mesh, e.g. chicken wire). In this way new substrate with limestone character can be generated in situ. Coral nubbins inserted into the mesh (cathode) during electrolysis are cemented alive to the new substrate within 3 wk. The method combines the formation of a semi-natural substrate with the option of shortening the initial colonisation phase by implanting large numbers of coral nubbins within a short time. Options for reef rehabilitation are outlned.
\end{abstract}

KEY WORDS: Coral reefs - Coral transplantation Artificial substrates Reef rehabilitation

Coral reefs are subjected to growing pressure as a result of various impacts. Apart from natural disturbances such as heavy storm events or periodic outbreaks of predator populations (Cameron \& Endean 1981), human activities such as quarrying (Wells 1985), sediment influx (Kojis \& Quinn 1984) ship grounding (Curtis 1985), anchoring and, last but not least, diving tourism are currently leaving their marks in reef areas (overview by Craik et al. 1990).

Although some of these stresses are single events, natural recovery often cannot be observed after a period of years or even decades (Done et al. 1991, Clark \& Edwards 1995). Various approaches to the restoration and reinstallation of coral coenoses have been discussed and tested (Harriott \& Fisk 1988). If natural recovery is likely, the process can be enhanced by improving the substrate (e.g. consolidating mobile gravel) and, in addition, by offering artificial substrate as nuclei and stepping stones for spontaneous colonisation. Furthermore, early stages of natural succession can be skipped by transplantation of living coral

-E-mail: van_treeck@uni-essen.de fragments to seed new substrates, thus initiating and accelerating recolonization and framework creation (Auberson 1982). Rinkevich (1995) proposed coral transplantation for reef restoration and management as being probably the best approach today to improving and preserving biodiversity on coral reefs.

Some limitations of substrate modification and transplantation are (1) the labour and cost intensity of coral transplantation (Harriott \& Fisk 1988), and (2) the introduction of large amounts of alien material (Clark \& Edwards 1995) onto the reef, which is hardly compatible with the requirements of restoration to a nature-like state (Schuhmacher 1996). We report here on experiments which tested the feasibility of combining the in situ creation of a nature-like substrate with the simultaneous seeding of the substrate with coral transplants. Calcium carbonate, the major component of this substrate, is deposited in situ from the seawater and only a minimal amount of alien material has to be introduced. Transplantation of coral nubbins is done by using the deposition process itself to attach the nubbins onto the new substrate. Such an approach may be able to overcome some of the limitations mentioned above.

Method, materials and locality. The in situ formation of semi-artificial substrate by electrolysis was proposed and described by Hilbertz et al. (1977) and Hilbertz $(1988,1992)$ and further developed by Schuhmacher \& Schillak (1994) and Goreau \& Hilbertz (1997). In brief, the principle is that of a galvanic cell. The calcium and magnesium ions that abound in seawater can be deposited on a given template by pure electrochemical deposition. When connected to a DC power supply, magnesium and calcium minerals precipitate on the cathode while chlorine and oxygen evolve around the anode. The accreted material consists mainly of calcium carbonate and is chemically similar to reef limestone (Meyer \& Schuhmacher 1993). 


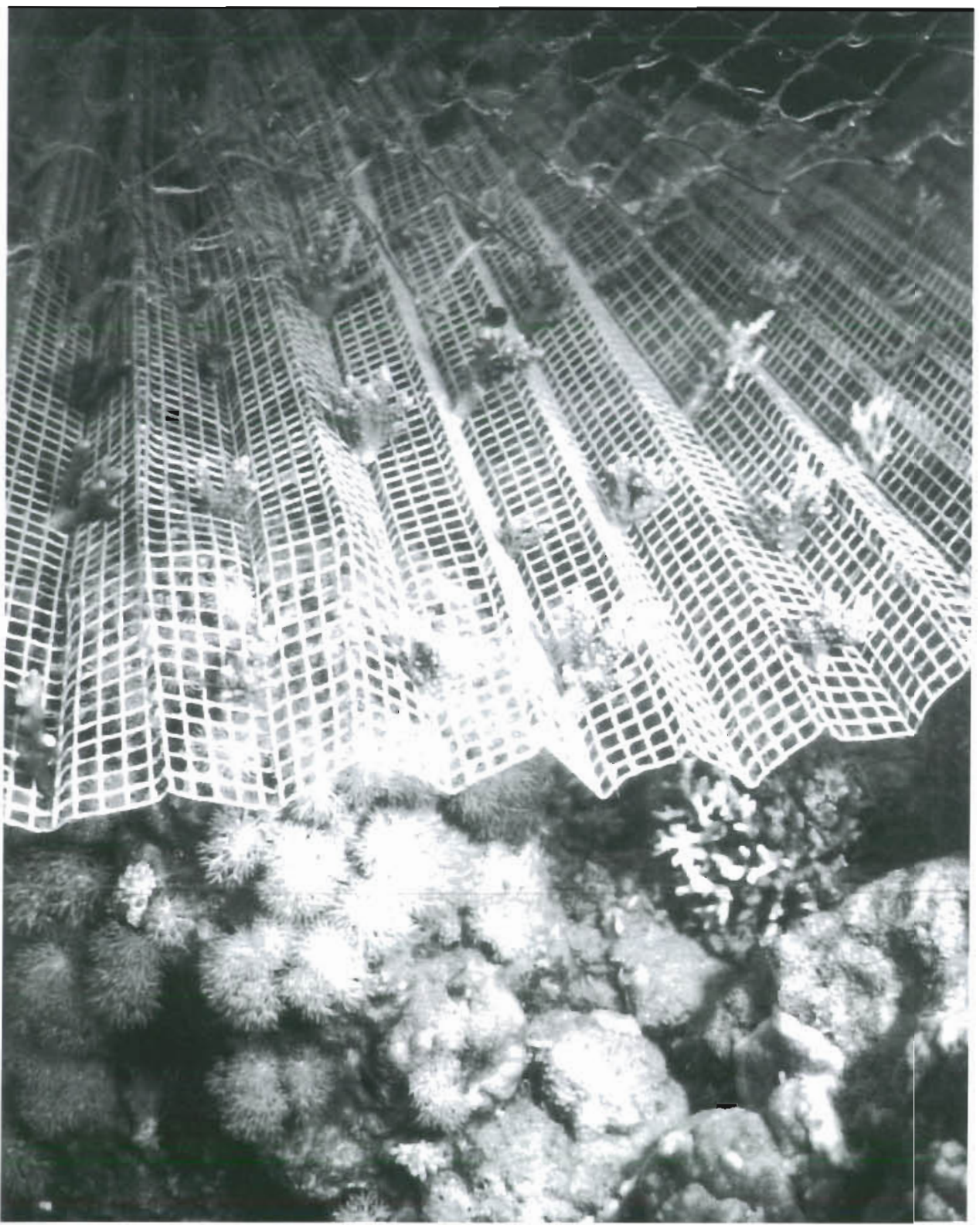

Fig. 1. Test square TS $-18 \mathrm{~m}$, 2 wk after installation

The cathode may consist of any conductive material in any shape desired. After several test series we prefer non-galvanised steel mesh (e.g. chicken wire). The anode may be made of carbon, lead or titanium. A direct current ranging from 1 to $24 \mathrm{~V}$ with a density of approximately $3 \mathrm{~A} \mathrm{~m}^{-2}$ cathodic surface gave the best results. As voltage is not a critical factor, considerable variations can be tolerated. Higher current densities result in faster precipitation but the balance between brucite $\left[\mathrm{Mg}(\mathrm{OH})_{2}\right]$ and aragonite $\left(\mathrm{CaCO}_{3}\right)$ shifts towards brucite, forming weak and fragile brucite layers. The thresholds vary with conditions in the electrolyte and cannot be given precisely

In general., high water temperature and high salinity support accretion. Strong hydraulic currents improve the material by reducing the $\mathrm{pH}$ gradient around the cathode, thus enlarging the proportion of calcium carbonate in the mineral deposition. A more detailed description of the accretion technology including cost estimation is given by Hilbertz (1992).

Within 2 mo a coating with a thickness of 5 to $10 \mathrm{~mm}$ may form on the mesh. Given a constant electrical current, the precipitation rate follows a negative asymptotical function against time. While the initial coating consists mainly of brucite, the proportion of calcium carbonate increases with the precipitation process, since the growing mineral layer induces a screening off of the electrical field and consequently lower $\mathrm{pH}$ values supporting the preferential deposition of calcium carbonate 
After precipitation has reached the desired thickness the electrodes are disconnected and marine organisms can settle on the new substrate. Spontaneous settlement by benthic organisms while electrolysis is in progress has been reported from experiments with very low current densities (Schuhmacher \& Schillak 1994).

The study site was located on the Jordanian coastline in the northern Gulf of Aqaba (Red Sea) about $10 \mathrm{~km}$ south of Aqaba, just in front of the Marine Science Station.

One test square (TS) was installed at each of 4 depths $(-1 m,-6 m,-12 m$ and $-18 \mathrm{~m}$ ) on the fore reef. Each TS was made of non-galvanised steel mesh $(1 \times 3 \mathrm{~m})$ with a wire thickness of $1 \mathrm{~mm}$ and $a$ mesh width of $10 \mathrm{~mm}$. The $3 \mathrm{~m}^{2}$ mesh of each TS presented an active cathodic surface of $1.8 \mathrm{~m}^{2}\left(0.6 \mathrm{~m}^{2}\right.$ cathodic surface per $\mathrm{m}^{2}$ mesh). Each TS was placed on the sea bed, and the edges were tied to natural coral rock with steel wire. This wire will also be coated by the precipitation; thus contact zones between coral rock and steel matrix become cemented together we inserted the TSs into the natural bottom morphology, choosing sites where the TSs could be orientated horizontally and the irradiance regime was approximately uniform.

Previous findings indicated heavy grazing activities by fish (van Treeck et al. 1996). To reduce the grazing pressure by herbivores we enhanced the roughness of the mesh by zig-zag folding resulting in a final projection area of about $1 \times$ $1.5 \mathrm{~m}$ for each TS (Fig 1). The folding forms recesses difficult to reach for grazing fishes and sea urchins (Day 1985, Carlton \& Sammarco 1987).

Using scuba diving, we collected coral colonies (mostly branching species) at random in the proximity of the respective transplant site and at approximately the same depths. Source colonies were broken in situ into fragments and these nubbins were inserted into the mesh (Figs. 1 \& 2). Each TS was seeded with a total of 100 nubbins from 4 different species, 25 nubbins from each species. The species transplanted to the various TSs were selected on the basis of the community composition in the proximity of the respective transplant sites. We chose species typical and common at the respective sites (Table 1). Most of the chosen species are known to have a high ability to form new colonies out of fragments (Highsmith 1982, Harrison \& Wallace 1990, Richmond \& Hunter 1990).
Transplantation is quite simple. Two experienced divers were able to collect the required corals, fragment them and transplant 150 to 200 nubbins within $1 \mathrm{~h}$ of diving. After the nubbins had been transplanted, the TS was connected to the negative pole of a DC power supply (forming the cathode) and an anode of titanium mesh was placed about $20 \mathrm{~cm}$ above each square. Each TS was electrified at $9.8 \mathrm{~V}$ and $5 \mathrm{~A}$ for

Table 1. Species composition in the different TSs (numbers of nubbins)

\begin{tabular}{|lcccc|}
\hline & $\begin{array}{c}\text { TS } \\
-1 \mathrm{~m}\end{array}$ & $\begin{array}{c}\text { TS } \\
-6 \mathrm{~m}\end{array}$ & $\begin{array}{c}\text { TS } \\
-12 \mathrm{~m}\end{array}$ & $\begin{array}{c}\text { TS } \\
-18 \mathrm{~m}\end{array}$ \\
\hline $\begin{array}{l}\text { Stylophora pistillata } \\
\text { Pocillopora damicornss }\end{array}$ & 25 & 25 & 25 & 25 \\
$\begin{array}{l}\text { Acropora variabilis } \\
\text { Acropora squarrosa }\end{array}$ & 25 & 25 & 25 & 25 \\
$\begin{array}{l}\text { Montipora danae } \\
\text { Pavona varians }\end{array}$ & 25 & 25 & & 25 \\
\hline
\end{tabular}



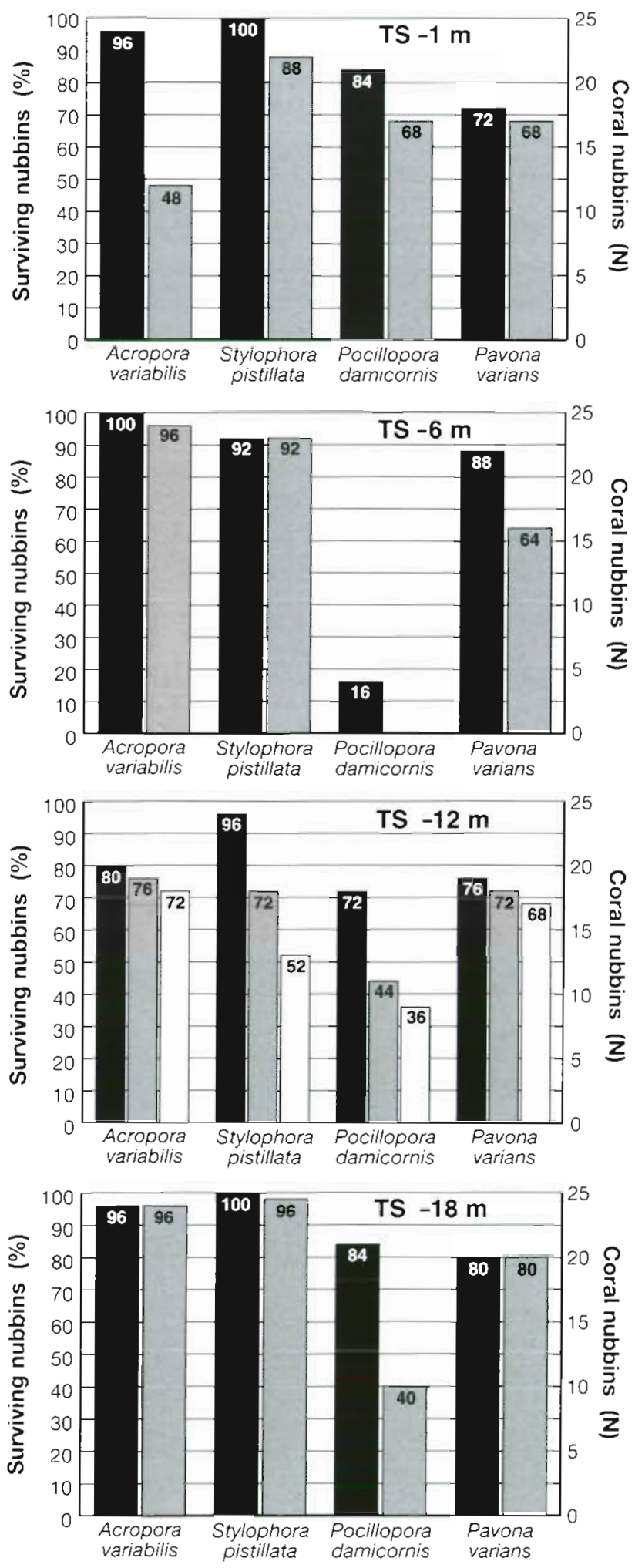

$\square$ mo $\square 7 \mathrm{mo} \quad \square 12 \mathrm{mo}$

Fig. 3. Proportion of nubbins $(\%)$ found alive after 3,7 and (for TS $-12 \mathrm{~m} / 1.2 \mathrm{mo}$. Exact percentage given on bars. Right-hand $y$-axis gives absolute numbers of nubbins
$18 \mathrm{~h}$ per day, supplying the cathodic surface of the mesh with a current density of approximately $2.8 \mathrm{~A} \mathrm{~m}^{-2}$ The $6 \mathrm{~h}$ break was necessary to avoid potential damage to the power supply during the hottest part of day. The precipitation process was checked daily during the first week. After 2 mo the electrodes were disconnected and the cables and anodes were taken out of the water. Each TS was inspected after 3, 7, and (in the case of TS $-12 \mathrm{~m}) 12 \mathrm{mo}$.

Results and discussion. A few hours after precipitation started a whitish fallout could be observed on the cathode. Initially, minerals were not deposited uniformly over the cathode but at higher rates in areas close to coral fragments. After 5 d the mean thickness of the precipitation layer was 0.5 to $1 \mathrm{~mm}$ while thicknesses of 1 to $2 \mathrm{~mm}$ were reached around the living nubbins. This phenomenon is not yet understood. With the growing accretion layers precipitation becomes more uniform-differences in accretion rates are no longer detectable. This may be a result of the screening off of the electrical field

After $2 \mathrm{wk}$ the accreted material started to cement the coral fragments to the mesh. A gentle touch with bare fingers confirmed that the nubbins were no longer mobile. Visual observation showed no damage to the coral tissue in the vicinity of the cathode (the mesh). This was surprising because $\mathrm{pH}$ values in close proximity to the cathodic surface may rise to as high as 11 (Schuhmacher \& Schillak 1994). After $8 \mathrm{wk}$ all the implanted fragments were well cemented to the mesh with the precipitation around them reaching a thickness of 6 to $8 \mathrm{~mm}$ (Fig. 2).

On all TSs the mortality of the implanted nubbins was rather low compared to the rates for nubbin transplants given in other investigations (reviewed in Harriott \& Fisk 1988). The data presented refer to survival rate as amount of nubbins found in original position. and alive on the respective TSs. Fig. 3 shows the survival rates of the various species at different depths after 3,7 and 12 mo. Losses were probably due to wave action, grazing activities, predation and death caused by intrinsic factors.

After a period of 3 mo, more than $80 \%$ of all implanted nubbins were still alive. An exception was the Pocillopora damicornis stock on TS $-6 \mathrm{~m}$, of which only $16 \%$ survived the first $3 \mathrm{mo}$. On TS $-12 \mathrm{~m}$, which was installed 5 mo earlier, the Acropora squarrosa nubbins showed mortality rates of $28 \%$ after 3 mo, rising to $56 \%$ after 7 mo. The Stylophora pistillata nubbins displayed a very similar pattern. The latter relatively high mortality values are an artefact. Between the fifth and the eighth week of the experiment, the rope that held the anode above the mesh fell down, causing a very strong electrical field around the area where the A. squarrosa and $S$. pistillata nubbins had 
been placed. We observed heavy precipitation of alkaline brucite, resulting in the death of some $A$. squarrosa and $S$. pistillata nubbins due to coverage by this material.

During the first inspection of the TSs, after 3 mo, it was not possible to locate all of the nubbins that had originally been inserted. These fragments may have been swept away by the current or picked out by fishes. We observed fishes (Labrids e.g. Thalassoma spp., Cheilinus abudjubbe) moving some coral fragments while searching for invertebrates living in the skeletons of fresh nubbins. We found some of the missing nubbins on the sea bed close to the TSs.

Some of the Acropora nubbins were affected by the corallivorous snail Drupella cornus, which is common in shallow waters in the Gulf of Aqaba. The death of at least $12 \%$ (3) of the Acropora nubbins from TS $-1 \mathrm{~m}$ was caused by $D$. cornus. This snail is mainly nocturnal (Schuhmacher 1992) but specimens were found feeding on the 3 nubbins during daytime. It can be assumed that $D$. cornus may be responsible for even more fragment deaths. The snail feeds preferentially on Acropora species (Al Moghrabi 1997).

Apart from the above-mentioned impacts on nubbins, a variable susceptibility to the treatment as a whole can be seen in the mortality patterns of the different species. Yap et al. (1992) reported high rates of mortality of Pocillopora transplants due to fragmentation and transplantation stress. The high mortality rate of our $P$. damicornis nubbins confirms their findings. Indeed, $P$. damicornis was not to be found as living fragments on the reef. Thus fragmentation rather than high alkalinity during the electrolysis seems to have been the major cause of death for the Pocillopora nubbins. In contrast, $87 \%$ of the Stylophora pistillata nubbins were still alive on the TSs after 7 mo. Although $S$. pistillata is not mentioned among the species frequently propagating by fragmentation (Highsmith 1982), living fragments could sometimes be encountered on the reef. Tissue fragmentation could regularly be observed in old $S$. pistillata colonies where the centre has died off. Similarly the crests and lobes of the irregularly growing 'crusts' of Pavona varians became separated by dead parts in older colonies. Fragmentation trauma should not be too heavy in these species. The disappearance of approximately $20 \%$ of the $P$. varians nubbins from the TSs could rather be explained by the fact that the crustose specimens could not be transplanted as easily as the branching ones by inserting the fragments into the mesh itself. The nubbins were placed in the corner formed by the zig-zag folding. As a result, not all nubbins were attached firmly to the mesh at the very beginning of accretion. In contrast to the branching species, the $P$. varians nubbins were not found dead on the TSs but disappeared due to wave action or biogenic disturbances such as fish grazing. The survival of the remaining nubbins was approximately $90 \%$, supporting the characterisation of Pavona as a suitable candidate for transplantation purposes (Plucer-Rosario \& Randall 1987). A similar situation holds true for Montipora danae on TS $-12 \mathrm{~m}$. In further experiments the method used for fixing fragments of crustose species to the mesh will need to be modified.

Conclusion and outlook. The method presented meets some of the major demands for reef rehabilitation. It provides a nature-like substrate with limestone character generated in situ predominately with genuine material. The time needed for natural colonisation is shortened by transplanting scleractinian corals as main framework builders from the very start.

Further investigations might be able to identify coral species with low sensitivity to our specific method from the variety of common species already known as sources for transplantation (Yates \& Carlson 1992).

After a year of experience with our method in the field we are optimistic that its easy handling makes it applicable for use on a larger scale. With the in situ formation of semi-artificial, appropriately designed substrate, furnished by living corals, a new tool is available to insert nuclei and stepping stones for the rehabilitation of denuded reef areas as well as to create de novo coral-inhabited structures on the seabed. They may blend more closely into genuine local substrate conditions than the other methods and materials used up to now.

Acknowledgements. This research was funded by the Deutsche Forschungsgemeinschaft within the priority program 'Biogene Sedimentation-Riffevolution' The work was possible within the framework of cooperation between the University of Essen and the Marine Science Station Aqaba (Jordan). Our thanks are due to Dr Ahmed Abu Hilal (Director) and all the staff of MSS Aqaba. We also acknowledge the invaluable assistance of Markus Paster and Lutz Kuhrau in the underwater installations. Heraeus Elektrochemie $\mathrm{GmbH}$ kindly provided the anode material. Valuable comments on the manuscript were made by anonymous reviewers. Dr E. G. Maddocks linguistically reviewed the English text.

\section{LITERATURE CITED}

Al Moghrabi S (1997) Bathymetric distribution of Drupella cornus and Coralliophila violacea in the Gulf of Aqaba (Jordan). Proc 8th Int Coral Reef Symp (in press)

Auberson B (1982) Coral transplantation: an approach to reestablishment of damaged reefs. Kalikasan 11:158-172

Cameron M, Endean R (1981) Renewed population outbreaks of a rare and specialised carnivore (the starfish Acanthaster planci) in a complex high diversity system. Proc 4th Int Coral Reef Symp 2:593-596

Carlton JH, Sammarco PW (1987) Effects of substratum irregularity on success of coral settlement: quantification by comparative geomorphological techniques. Bull Mar Sci $40: 85-98$ 
Clark S, Edwards A (1995) Coral transplantation as an aid to reef rehabilitation: evaluation of a case study in the Maldive Islands. Coral Reefs 14:201-213

Craik W, Kenchıngton R, Kelleher G (1990) Coral reef management. In Dubinsky $Z$ (ed) Coral reefs. Elsevier. Amsterdam, p 453-467

Curtis C (1985) Investigating the reef recovery following a freighter grounding in the Key Largo National Marine Sanctuary. Proc 5th Int Coral Reef Symp 6:471-476

Day R (1985) The effects of refuges from predators and competitors on sessile communities on a coral reef. Proc 5th Int Coral Reef Symp 4:41,-45

Done TJ, Dayton PK, Ddyton AE, Steger R (1.991) Regional and local variability in recovery of shallow coral communities: Moorea, French Polynesid and central Great Barrier Reef. Coral Reefs 9:183-192

Goreau TJ, Hilbertz W (1997) Reef restoration using seawater electrolysis in Jamaica. Proc 8th Int Coral Reef Symp (in press)

Harriott VJ, Fisk DA (1988) Coral transplantation as a reef management option. Proc 6th Int Coral Reef Symp 2: 375-379

Harrison PL, Wallace CC (1990) Reproduction, dispersal and recruitment of scleractinian corals. In: Dubinsky $Z$ (ed) Coral reefs. Elsevier, Amsterdam, p 133-206

Highsmuth RC (1982) Reproduction by fragmentation in corals. Mar Ecol Prog Ser 7:207-226

Hilbertz W (1988) Growing and fading structures: experiments, applications, ideas. Mitt Sonderforschungsbereich 230 'Natürliche Konstruktionen-Leichtbau in Architektur und Natur' 2:107-114

Hilbertz W (1992) Solar generated bulding material from seawater as a sink for carbon. Ambio 21:126-129

Hilbertz W, Fletcher D, Krausse C (1977) Mineral accretion technology: applications for architecture and aquaculture. Industr Forum 8:75-84

Kojis BL, Quinn NJ (1984) Seasonal and depth variation in

This note was presented by R. P. M. Bak (Senior Editorial Advisor), Texel, The Netherlands fecundity of Acropora palifera at two reefs in Papua New Guinea. Coral Reefs 3:156-172

Meyer DE, Schuhmacher H (1993) Ökologisch verträgliche Bauprozesse im Meerwasser Geowissenschaften 11: $408-412$

Plucer-Rosario GP, Randall RH (1987) Preservation of reef coral species by transplantation: an examination of their recruitment and growth. Bull Mar Sci 41:585-593

Richmond RH, Hunter CL (1990) Reproduction and recruitment of corals: comparison among the Caribbean, the tropical Pacific and the Red Sea. Mar Ecol Prog Ser 60: $185-203$

Rınkevich B (1995) Restoration strategies for coral reefs damaged by recreational activities: the use of sexual and asexual recruits. Restoration Ecology 3:241-251

Schuhmacher H (1992) Impact of some corallivorous snails on stony corals in The Red Sea. Proc 7th Int Coral Reef Symp $2: 840846$

Schuhmacher H (1996) Starthilfe für künstliche Riffe. Spektrum der Wissenschaft 3:66-73

Schuhmacher H, Schillak L (1994) Integrated electrochemical and biogenic deposition of hard material-a nature-like colonization substrate. Bull Mar Sci 55:672-679

van Treeck P, Schuhmacher H, Paster M (1996) Grazing and bioerosion by herbivorous fishes - Key processes structuring coral reef communities. In: Reitner J, Neuweiler F, Gunkel F (eds) Göttinger Arb Geol Palàont Sb2:133-137

Wells SM (1985) What's happening to coral reefs? Part II. ICLARM Newsletter 8:6-8

Yap HT, Alino PM, Gomez ED (1992) Trends in growth and mortality of three coral species (Anthozoa; Scleractinia), including effects of transplantation. Mar Ecol Prog Ser 83: $91-101$.

Yates K, Carlson BA (1992) Corals in aquarıums: how to use selective collecting and innovative husbandry to promote reef conservation. Proc 7th Int Coral Reef Symp 2: $1091-1095$

Manuscript first received: May 15, 1996

Revised version accepted: March 6, 1997 